\title{
Endoscopic negative-pressure therapy for duodenal leakage using new open-pore film and polyurethane foam drains with the pull-through technique
}

Few reports have described the use of endoscopic vacuum therapy (EVT) for duodenal defects [1-4]. We treated a complicated duodenal leak with EVT using the pull-through technique with a new type of open-pore polyurethanefoam drain (OPD) [5] and a novel type of open-pore film drain (OFD).

Construction of an OFD is shown in > Video 1. First the distal ends of two drainage tubes (Ventrol; $12-18 \mathrm{Fr} \times 120 \mathrm{~cm}$; Covidien, Argyle, Ireland) are connected. This coupling segment is then wrapped with open-pore polyurethane-foam or a very thin double-layered film (Suprasorb CNP drainage film; Lohmann \& Rauscher, Germany) ( $\triangleright$ Fig. 1 ). The diameter of the OPD is $1.5-3 \mathrm{~cm}$ and of the small-bore OFD is 4-6 mm (> Fig.2). Both drain types can be placed by the pull-through technique along an intestinal-cutaneous fistula. The oral end is passed out nasally and a vacuum is applied to drain the intraluminal secretions; the distal end is passed out cutaneously ( Fig. 3 ).

We report a 53-year-old patient who presented for endoscopic examination with a persisting duodenocutaneous fistula after a very complicated course including multiple operations. Duodenal secretions were running along an intraabdominal drain placed next to the duodenum and a 2-cm transmural defect of the duodenal wall was found near to the papilla of Vater. The operative drain could be seen through this defect.

An OPD was inserted using the pullthrough technique following the course of the operative drain. The foam was pulled into the internal opening of the duodenal fistula. Application of negative pressure with an electronic vacuum device ( $\mathrm{KCl}$ Activac; setting $125 \mathrm{mmHg}$, continuous, intensity high) resulted simultaneously in closure of the defect around the tube, collapse of the duodenal lumen, and internal drainage of duodenal secretions. The drainage of secretions cutaneously stopped immediately.
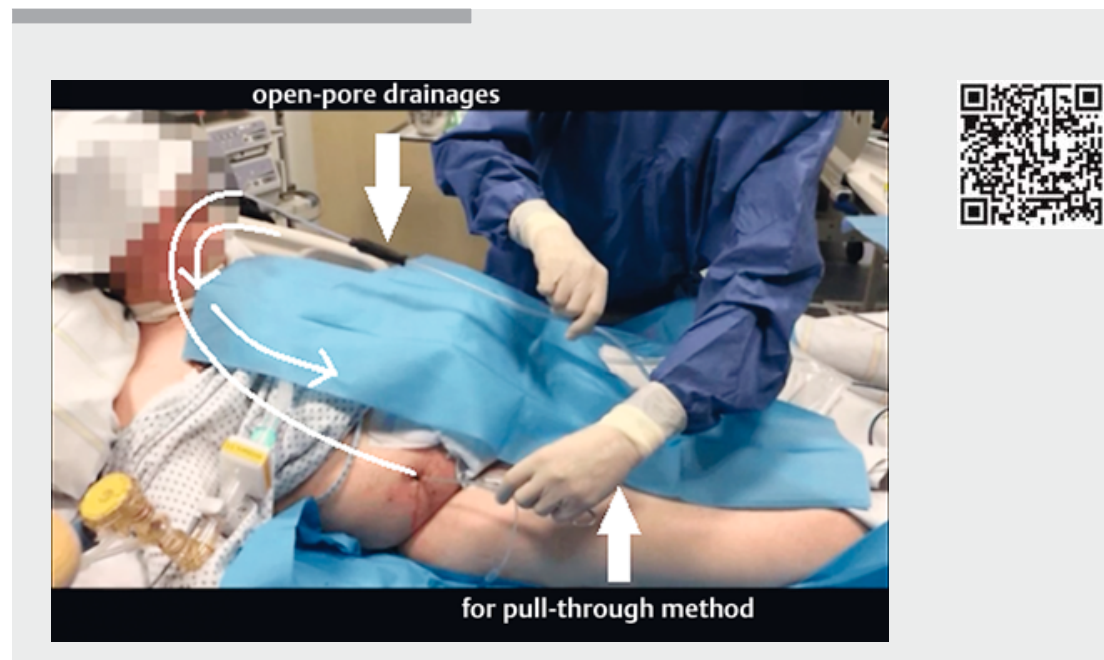

Video 1 Construction of an open-pore film drain (OFD) for the pull-through method is demonstrated. Different types of pull-through drains are illustrated. Insertion of an openpore polyurethane-foam drain (OPD) is shown using the pull-through technique in a patient with duodenal leakage.

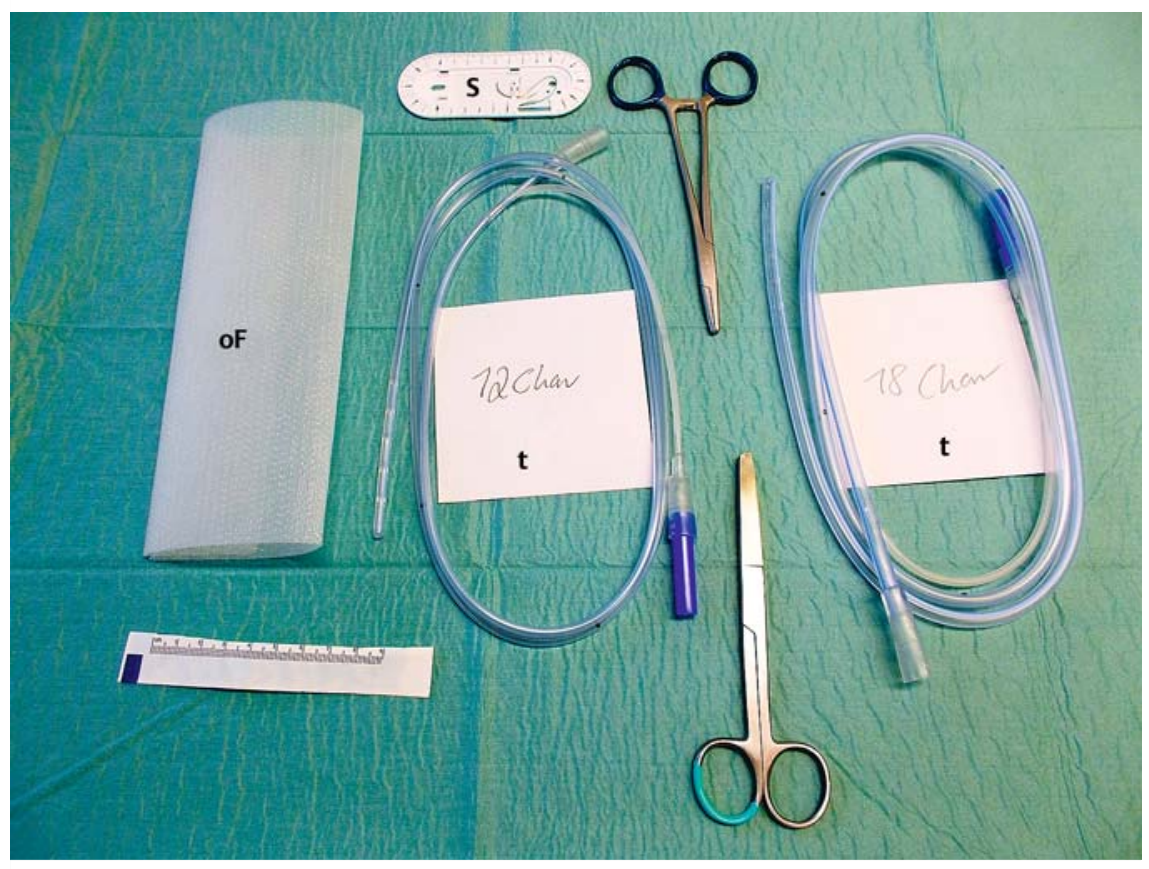

-Fig. 1 Materials for construction of an open-pore film drain for the pull-through technique, including gastric tubes with diameters of $12 \mathrm{Fr}$ and $18 \mathrm{Fr}(\mathrm{t})$, open-pore film (oF), and a suture (S). 


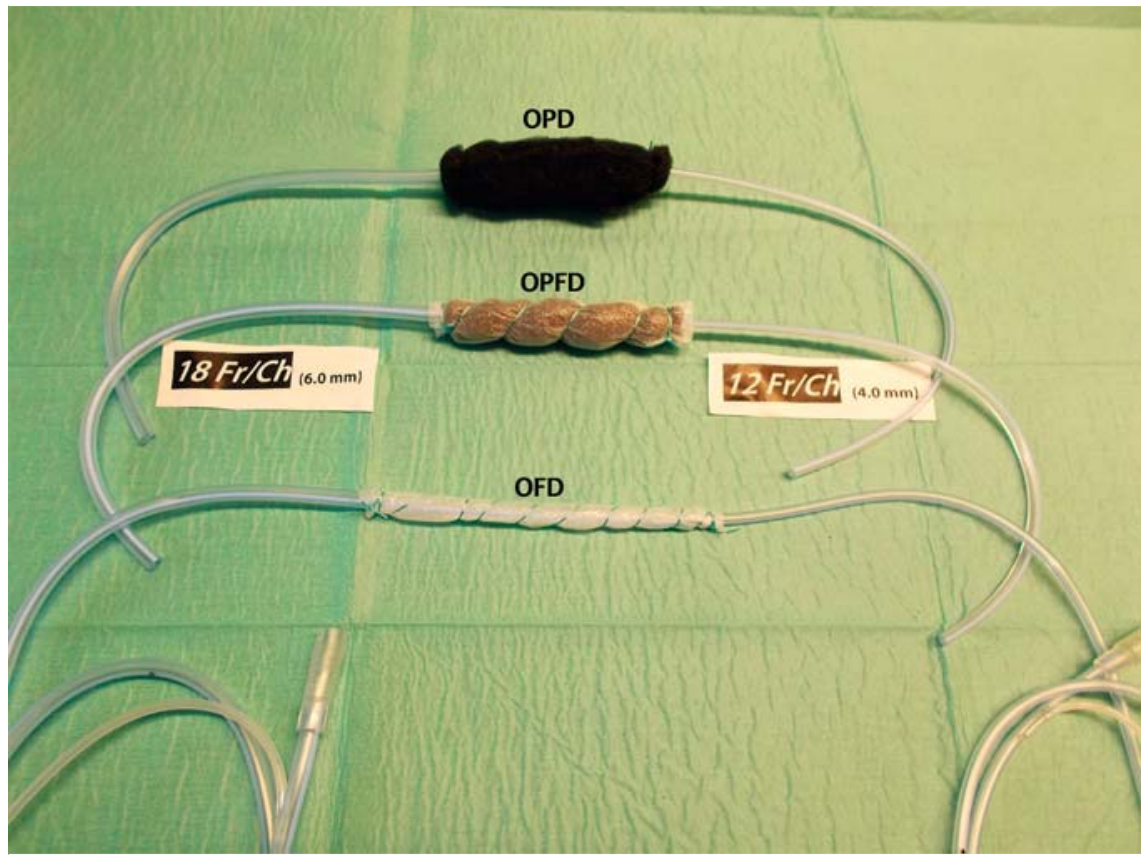

- Fig. 2 The different types of drains that can be used for the pull-through technique in endoscopic negative-pressure therapy include the open-pore polyurethane-foam drain (OPD), an OPD coated with an open-pore film (OPFD), and the new open-pore film drain (OFD).

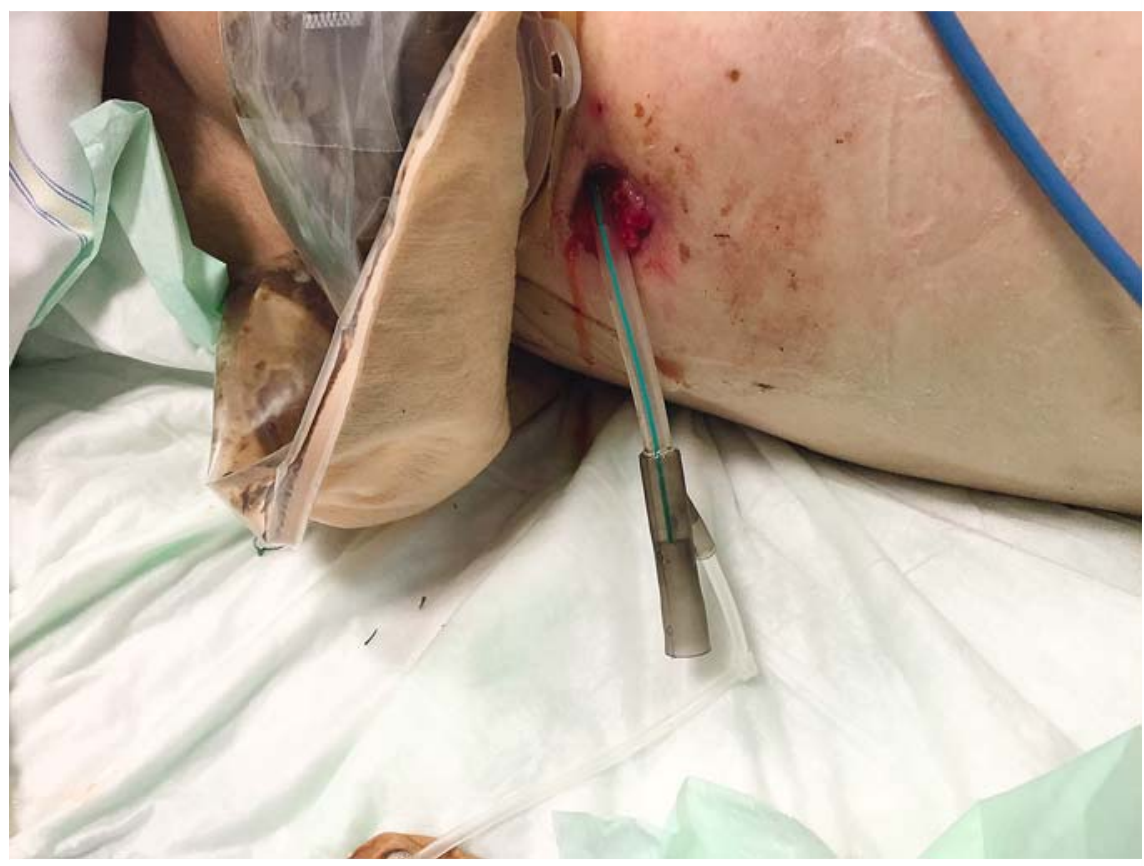

- Fig. 3 One end of the tube from the open-pore polyurethane-foam drain is passed out cutaneously along the operative fistula channel.

On day 4, the OPD was replaced, before being changed to a small-bore OFD on day 8 , which was again replaced on day 11. The size of the opening of the defect shrank to a small fistula. EVT was continued for 14 days in total, and the OFD was then removed. Follow-up endoscopies 1 month and 3 months after the end of therapy revealed complete healing ( Fig.4).

Endoscopy_UCTN_Code_TTT_1AO_2AI
Competing interests

Gunnar Loske is a consultant for Lohmann \& Rauscher GmbH \& Co. KG. The other authors have no conflict of interest to declare.

The Authors

Gunnar Loske'1, Marc Liedke², Erik Schlöricke², Thomas Herrmann ${ }^{3}$, Frank Rucktaeschel ${ }^{3}$

1 Department for General, Abdominal,

Thoracic and Vascular Surgery, Katholisches Marienkrankenhaus Hamburg gGmbH, Hamburg, Germany

2 Department for Abdominal, Thoracic and Vascular Surgery, Westküstenklinikum Heide, Heide, Germany

3 Department for Internal Medicine, Gastroenterology, Hemato-Oncology, Nephrology and Endocrinology,

Westküstenklinikum Heide, Heide, Germany

\section{Corresponding author}

\section{Gunnar Loske, MD}

Department for General, Abdominal, Thoracic and Vascular Surgery, Katholisches Marienkrankenhaus Hamburg gGmbH, Alfredstrasse 9, 22087 Hamburg, Germany Fax: $+49-40-25461400$

loske.chir@marienkrankenhaus.org

\section{References}

[1] Loske G, Schorsch T, Mueller CT. Endoscopic intraluminal vacuum therapy of duodenal perforation. Endoscopy 2010; 42: E109

[2] Loske G, Schorsch T. Intraluminal vacuum therapy - A new endoscopic approach in the treatment of duodenal leakage. Endoskopie heute 2010; 23: 267-269

[3] Glatz T, Fischer A, Hoeppner J et al. Vacuum sponge therapy using the pull-through technique via a percutaneous endoscopic gastrostomy to treat iatrogenic duodenal perforation. Endoscopy 2015; 47: E567E568

[4] Loske G, Rucktäschel F, Schorsch T et al. Successful endoscopic vacuum therapy with new open-pore film drainage in a case of iatrogenic duodenal perforation during ERCP. Endoscopy 2015; 47: E577 -E578

[5] Fischer A, Thimme R, Hopt UT et al. Twosided sponge (TSS) treatment: Description of a novel device and technique for endoscopic vacuum treatment (EVT) in the upper gastrointestinal tract. Endosc Int Open 2016; 4: E937-E940 

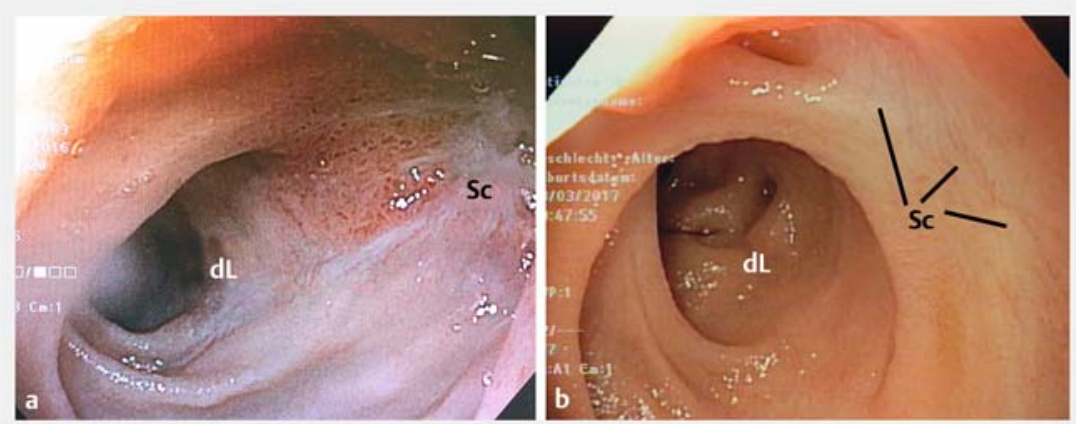

- Fig. 4 Endoscopic views showing complete healing of the duodenal defect: a 28 days after the end of therapy; $\mathbf{b} 3$ months after the end of therapy. Sc, scare; dL, duodenal lumen.

\section{Bibliography}

DOI https://doi.org/10.1055/s-0043-119346

Published online: 25.9 .2017

Endoscopy 2017; 49: E300-E302

(c) Georg Thieme Verlag KG

Stuttgart · New York

ISSN 0013-726X

\section{ENDOSCOPY E-VIDEOS \\ https://eref.thieme.de/e-videos}

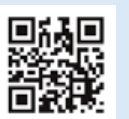

Endoscopy E-Videos is a free access online section, reporting on interesting cases and new techniques in gastroenterological endoscopy. All papers include a high quality video and all contributions are freely accessible online.

This section has its own submission website at

https://mc.manuscriptcentral.com/e-videos 